\title{
Artelogie
}

artelogie Recherche sur les arts, le patrimoine et la littérature de l'Amérique latine

13 | 2019

Violeta Parra: authenticité, primitivisme et processus d'exotisme chez les artistes latino-américains.

\section{El empoderamiento de Violeta Parra y sus versos como espacio de enunciación múltiple y afirmación del sujeto femenino}

\section{Eleni Stagkouraki}

\section{(2) OpenEdition Journals \\ Edición electrónica \\ URL: http://journals.openedition.org/artelogie/3218 \\ DOI: $10.4000 /$ artelogie.3218 \\ ISSN: 2115-6395 \\ Editor \\ Association ESCAL \\ Referencia electrónica \\ Eleni Stagkouraki, «El empoderamiento de Violeta Parra y sus versos como espacio de enunciación múltiple y afirmación del sujeto femenino », Artelogie [En línea], 13 | 2019, Publicado el 07 enero 2019, consultado el 02 mayo 2019. URL : http://journals.openedition.org/artelogie/3218; DOI : 10.4000/ artelogie.3218}

Este documento fue generado automáticamente el 2 mayo 2019.

Association ESCAL 


\title{
El empoderamiento de Violeta Parra y sus versos como espacio de enunciación múltiple y afirmación del sujeto femenino
}

\author{
Eleni Stagkouraki
}

Si yo levanto mi grito no es tan solo por gritar

(Violeta Parra, "Yo canto la diferencia"

en Engelbert, 2017 [1978]: 146-150.)

El hecho de que Violeta Parra (1917-1967) resulte hoy un personaje subalternizado se evidencia por su exclusión del panteón de los 'grandes' escritores chilenos -lo que no ocurre con autores como Vicente Huidobro, Pablo de Rokha y por supuesto los premios Nobel Gabriela Mistral ${ }^{1}$ y Pablo Neruda- y su caracterización como "otra cosa" (ENGELBERT, 2017 [1978]: 22). No se trata aquí de un esfuerzo para su inclusión en el canon -no es eso lo que procuramos ni tampoco lo que ella deseaba; no en vano declaraba "yo canto la diferencia"-, sino mucho más de un intento de demostrar la construcción sistemática de su Otredad ${ }^{2}$ como método de justificación de su exclusión. Esa exclusión ha sido causa y al mismo tiempo resultado de su silenciamiento que, a su vez, se interpretaba a menudo como ausencia. ${ }^{3}$ No es así. La falta hasta el día de hoy de una edición comprensiva de la obra de Violeta Parra, una edición por ejemplo que incluyera las Décimas (escritas en los años 1957-58), sus canciones, pero también representaciones de sus tejidos o sus esculturas, no se relaciona con la inexistencia de estas obras, sino con las prácticas de subalternización ${ }^{4}$ para con Violeta Parra, esto último en dos niveles: como persona y como artista. 


\section{Violeta Parra puesta en los márgenes}

\section{Subalternizando a la persona}

2 Tematizar la marginalización de Violeta Parra como persona es una tarea clave para el mejor entendimiento de su consecuente subalternización como artista, como también de los modos con los que ella salió de esta posición marginal, como veremos a continuación. Además, hay que darle a este asunto la importancia que merece, ya que muchas veces la historia de la humanidad ha mostrado que un ser humano puede sobrevivir a la desautorización profesional, pero no a la anulación personal. Enseguida se hará evidente por qué es necesaria también la reivindicación y la recuperación de la propia identidad e integridad de la persona de Violeta Parra.

3 Su subalternización como persona empezó y se llevó a cabo sobre todo durante el tiempo de su vida, basada en atributos arbitrarios, malinterpretaciones y consideraciones subjetivas/descalificantes. Partiendo, por un lado, de la malinterpretación de contradicciones inherentes a ella y por otro, de prejuicios sociales, no dudaron en considerarla "una persona loca" (ENGELBERT, 2017 [1978]: 111) que "estaba cucú" (SUBERCASEAUX y LONDOÑO, 1976: 49-50). Estas contradicciones que se encuentran reproducidas a menudo en su obra están vinculadas sin duda con aspectos de su carácter: por un lado su necesidad de recibir y dar amor y cariño y por otro la imposibilidad de una convivencia en pareja ${ }^{5}$; por un lado la seguridad de sí misma y de su valor artístico, por ejemplo exigiendo silencio para empezar su presentación (PINOCHET COBOS, 2010: 87), y por otro la inseguridad expresada en manifestaciones de baja autoestima: "soy muy poca cosa" o "Sólo un costrón inhumano" o "llamé a una puerta de fierro,/ como si yo fuera un perro" o "me sobrenombran "maleza"/ porque parezco un espanto" o "soy fea" (PARRA, 1972); por un lado su "conservadurismo" por su respeto hacia normas sociales y expresiones artísticas tradicionales y por otro su progresismo por su ruptura con el ideal de la mujer de la época como vamos a ver más adelante; por un lado su agradecimiento por la vida (gracias a la vida que me ha dado tanto, "Gracias a la vida" en ENGELBERT, 2017 [1978]: 224-226) y por otro su juramento contra todos y todo ("Maldigo del alto cielo" en ENGELBERT, 2017 [1978]: 220); o por un lado su religiosidad con un profundo sentido de culpa, la apelación frencuente a la Virgen María (PINONCHET COBOS, 2010: 83) y a Jesús y por otro el cuestionamiento de la iglesia o sea la crítica a la degradación de las instituciones eclesiásticas (MILLARES, 2000: 174). También se consideró poco coherente el intercambio de subjetividades con objetividades y el hecho de que se dedicaba por un lado a la poesía de amor y por otro a la sátira política, aunque no vemos cómo esto último podría formar una contradicción y no una acción complementaria. En todo caso, aparte de que la contradicción es una característica constitutiva del ser humano, una mirada más cercana convencerá hasta al más escéptico de que aquí no se trata de comportamientos y consideraciones que se excluyan mutuamente y que no puedan coexistir. Poco tiene que ver la fe con la institución de la iglesia o las necesidades personales con los contratos sociales, aún si tomamos en cuenta que la sociedad chilena en el tiempo de vida de Parra no fue la de hoy. Tampoco es incompatible "el canto a la inocencia con la ironía y la acidez, con las que se pone en tela de juicio la validez de un sistema que oprime y amordaza, que legitima la pobreza, y con ella aliena y envilece a los desposeídos" (ibid.: 175). ¿O acaso no tenemos todos nuestros momentos de triunfo y 
desesperación, por grandes o pequeños que sean, independientemente de tiempos o geografías?

4 Respecto a los prejuicios sociales y clasistas, en los que se ven reflejadas las opresiones respectivas y en los que se basó la descalificación de Violeta Parra como persona, estos se relacionaban con su procedencia de y su aceptación por las clases bajas de la sociedad chilena: los campesinos, los obreros, los pobladores, los indígenas (RIQUELME, 2012: 1-13). Su pobreza y sus "modales campesinos", con lo que más bien se describía su sinceridad absoluta, su franqueza y su modo directo más allá de las convenciones sociales, fueron usados como argumentos en su contra y a favor de su presentación como lunática. A esto aportaba también su apariencia física y su estilo austero y descuidado (PINOCHET COBOS, 2010: 87) o, mejor dicho, lo que según los prejuicios sexistas de la época se interpretaba como tal, sobre todo en el momento en que las mujeres -como vamos a ver a continuación- tenían que ser bellas y cuidar mucho su aspecto (ibid.: 77-89), algo no muy distinto de lo que se promueve hoy día.

5 Se trata de una argumentación que se construye facil y frecuentemente por razones sexistas, clasistas o racistas para la marginalización de personas, grupos o movimientos. A Violeta Parra no le perdonaban su aspecto y sus modales campesinos, una de las justificaciones de su supuesta locura, basada como vimos en prejuicios clasistas. Con su descalificación como "locas", pero por razones esta vez racistas, fueron también confrontadas a menudo las mujeres negras, por lo que esta práctica fue tematizada por las teóricas del feminismo negro (cf HOOKS, 1990: 91, COMBAHEE RIVER, 2015 [1977]: 211). Respecto a motivos sexistas, a lo largo de la historia de las sociedades patriarcales las mujeres han sido consideradas a menudo "histéricas", "hipersensibles" o desmesuradamente "emocionales", en un esfuerzo de legitimar su subalternización frente a los hombres.

\section{Subalternizando a la artista}

"Pero los secretarios no te quieren (...)

Y te declaran la guerra a muerte (...)

Porque tú no te vistes de payaso

Porque tú no te compras ni te vendes"

("Defensa de Violeta Parra" (PARRA, 2017 [1969]: 185)

6 Aparte de la descalificación de Violeta Parra como persona a tiempos de su vida, las prácticas de su marginalización como artista, sobre todo como folclorista, y hasta su silenciamiento sistemático y la censura después de su muertre son de gran importancia.

7 Primero, la misma descalificación de Violeta Parra como persona tuvo repercusiones también en su perfil de artista. Exponiéndola como una persona perturbada y lunática, la presentaban como un personaje que no se debía tomar en serio ni se debía perder el tiempo, mucho menos con su obra, algo que la debe haber afectado mucho, ya que el arte y la creación artística fueron para ella su raison d'être (ENGELBERT, 2017 [1978]: 108).

8 A esta argumentación vino a sumarse el papel crucial de los medios de comunicación a partir de los mediados de la década de los 1960. Con el flujo de nuevas tendencias musicales a Chile, artistas tradicionales o de folclore como Violeta Parra y sus hermanos (ibid.: 121) se vieron excluidos como representantes del pasado y de formas "pasadas de moda". El efecto de esta evolución lo reforzó la doble subalternidad del caso de Violetta Parra como representante de una "realidad subcultural" y una "realidad subdesarollada 
latinoamericana" (Eduardo Martínez Bonati citado en ibid.: 135). La "realidad subcultural" se refiere al menosprecio del folclore como forma de arte, mientras que la "realidad subdesarollada latinoamericana" implica la realidad socio-económica del Chile de aquel entonces como un país de los $2 / 3$ del mundo (y no tercermundista o subdesarollado - cf. ESTEVA y MADHU, 1998, TALPADE MOHANTY, 2003, DIRLIK, 1997).

No obstante, la etapa crítica para el silenciamiento de la cantautora chilena fue durante la dictadura militar de Augusto Pinochet (1974-1990), esto por la censura política y la presentación parcial de su obra. Ya que la dictadura no pudo "silenciar por la fuerza ni el nombre ni las canciones de Violeta Parra" (ENGELBERT, 2017 [1978]: 122-123), permitió que se publicara en 1976 una edición en Santiago, en donde, sin embargo, faltaban sus canciones políticas, salvo una ("Cantores que reflexionan"). Como resultado de la censura impuesta, la obra de la Viola doliente (PARRA, 2017 [1969]: 185) se presentó de manera parcial, lo que le quitaba su sentido.

10 Como si esto no bastara, se llevó a cabo una malinterpretación intencionada de la obra editada, exponiendo a Violeta Parra como "representante del nacionalismo agrario, nostálgico y conservador" (ENGELBERT, 2017 [1978]: 123), lo que ella justo trataba de superar. Con eso, se intentó imponerle un dualismo inexistente en su pensamiento y su obra, es decir la lucha cultural entre la ciudad y el campo. Puede ser que la realidad social, económica y cultural varía y en parte sigue variando mucho entre el campo y los núcleos urbanos chilenos, pero lo que nos interesa y comentamos aquí es la disposición de la artista hacia esta diferencia. Como vamos a exponer más adelante, Violeta Parra, más que favorecer las divisiones, procuraba la construcción de puentes, también entre la ciudad y el campo; ella misma fue tal puente que copulaba estos espacios.

\section{Rompiendo con las normas sociales y artísticas de su época; una verdadera voz libertadora que sale de la posición marginal}

11 La voz de Violeta Parra molestaba porque sus palabras conectaban los oyentes con todos los que viven en silencio (HOOKS, 1989: 18) y sufren de las opresiones por todos los lados del mundo. Ella misma fue una voz libertadora ${ }^{6}$, cruzando las fronteras de la articulación -es decir pasando del silenciamiento a un lenguaje (propio)- y llevando a una nueva conciencia de sujeto que posibilitó su resistencia. La artista chilena supo transformar los márgenes ${ }^{7}$ en espacios abiertos con el potencial y la dinámica de una articulación artística, creativa y crítica. ${ }^{8}$ Es más, basándose en su experiencias históricas y culturales específicas logró tanto en su vida como en su obra salir de la posición marginal e introducirse en el sistema simbólico (cf. KROLL, 1999:25). En palabras de Patricio Manns uno de sus biógrafos-, Violeta Parra quiso y logró "ser diferente, manejarse sola e imponerse", sobre todo en las instancias de la manifestación de su Yo, instancias que él llama "apocalípticas" (Patricio Manns citado en ENGELBERT, 2017 [1978]: 117). Estas manifestaciones del Yo, es decir de la persona que se vuelve sujeto, demuestran el empoderamiento de Violeta Parra como persona y artista por la superación del estatus subalterno9. 


\section{Rompiendo con los ideales de la época respecto a las mujeres y su papel en la sociedad chilena}

12 Puede ser que Violeta Parra sufrió por la pobreza y las condiciones precarias durante su infancia, teniendo que trabajar desde sus cuatro años para aportar en una familia tempranamente acéfala de padre. Sin embargo, se desvió del porvenir típico de las mujeres de su clase y de su tiempo que hacía de las mujeres amas de casa, buenas esposas y-sobre todo- madres (RIQUELME, 2012: 9). No obstante, la consideración del hogar como lugar "natural" de las mujeres no fue un fenómeno ni solo chileno ni solo de aquel tiempo, sino que se manifestaba ya desde la conquista. ${ }^{10}$ Sea como sea, Violeta Parra prefirió no cumplir con las espectativas sociales de su época respecto a su género volviéndose una ama de casa, tolerando pasivamente a su marido y cuidando sólo a sus hijos y optó por la creatividad y su camino artístico.

Concretamente, rompía con tres ideales y valores "constitutivos de la identidad femenina" de su época: la belleza, el matrimonio y la maternidad (PINOCHET COBOS, 2010: 78-84). La belleza, tanto la interior, en forma de bondad y moralidad, como la exterior, con el cuidado del cuerpo, se consideraba una de las virtudes de las mujeres de la época. Como dejan observar las publicidades del aquel entonces, las mujeres debían cuidar su cuerpo usando cremas ("cremas de oro para un cutis lozano"), métodos de depilación ("para evitar los bigotes frondosos y poco atractivos") o "tónicos fru-frú" (“para el vigor, lozanía y mejoramiento general del ánimo", ibid.: 78). Nada más lejano para Violeta Parra, quien, aparte de tener un cuerpo y un rostro marcados por la viruela, no compartía tales preocupaciones. Así que por un lado partía del hecho de que se le consideraba fea: "si me acercaba yo un tanto,/ miraban como centellas/ diciendo que no soy bella/ ni pa'remedio un poquito./ La peste es un gran delito/ para quien tiene su huella" (“Aquí empiezan mis quebrantos" en PARRA, 1972). Por otro lado, ella misma optaba por una apariencia física simple y descuidada, sin maquillaje, y con eso más cercana a la gente para y por la cual ella cantaba.

Respecto al matrimonio y el establecimiento de un hogar y un ámbito familiar, ella lo experimentó dos veces, pero no dudó en caracterizarlo en su "Verso por matrimonio" (PARRA, 1972) como "infierno" y "condena". Se casó por primera vez a los veinte años, pero dejó el matrimonio después de once años de sufrimiento por la violencia, la infidelidad y las borracheras de su marido. Después de casarse por segunda vez, también sin éxito, siguió su vida con su guitarra al hombro, fiel a sí misma y a su música, intentando ganar su vida con dignidad y por medio de su propia fuerza. Violeta Parra experimentó la maternidad cuatro veces, dos en su primer matrimonio (ENGELBERT, 2017 [1978]: 106) y dos en su segundo, pero -siendo un espíritu inquieto- no se asentó. De los sentimientos de culpa por el hecho de que su hija Rosita Clara, quien sólo tuvo nueve meses, muriera de una pulmonía mientras ella estaba de viaje en Polonia, no se va a recuperar nunca:

De nueve meses yo dejo

mi Rosa Clara en la cuna.

"Com' esta maire, ninguna»

-dice el marí'o perplejo

o "No tengo perdón del cielo/ ni tampoco de los vientos;" ("Salgo de chile" en PARRA, 1972). También la infancia de sus hijos mayores, Ángel e Isabel, "se encontró siempre supeditada al proyecto artístico-cultural" de su madre (PINOCHET COBOS, 2010: 83). De 
estas consideraciones se deja concluir que Violeta Parra no sólo no se dejó oprimir por las reglas sociales vigentes para las mujeres de su época, sino que fue una mujer empoderada que luchó contra los prejuicios respecto a la identidad femenina, abriendo su propio camino como única dueña de si misma.

\section{Rompiendo con las normas artísticas de la época y la restricción de las mujeres artistas en ciertos espacios creativos - La renovación del folclore chileno}

16 También sus aportes en el mundo artístico y cultural de Chile y en consecuencia latinoamericano atestigua del empoderamiento de Violeta Parra. Como artista, logró no sólo con su escritura, sino también con su trabajo folclórico amplio, sus arpilleras, su cerámica, sus esculturas y sus pinturas, es decir con el conjunto de su expresión artística multidimensional, "la reivindicación de sus orígenes sin glorificaciones falsas y de un arte sin sofisticaciones al servicio del pueblo" (PARRA, 2006: 122). Aportó de manera fundamental en la recuperación de formas, estilos e instrumentos musicales chilenos que estaban por morir, como también en el descubrimiento de formas musicales nuevas como la cueca recortada, lo que llevó a algunos a hablar de ella como "descubridora de un Chile musical desconocido" (GONZÁLEZ, OHLSEN Y ROLLE, 2009: 385).

De central importancia es el trabajo de Violeta Parra sobre el folclore chileno. Puede ser que no fue la primera folclorista, ya que hubo otras y otros artistas que compartían sus preocupaciones en Chile como Margot Loyola y Antonio Acevedo Hernández (ENGELBERT, 2017 [1978]: 113), como también una ola de folclore a los años 1940 (expresado por ejemplo por Nicanor Molinare o Clara Solovera) y la ola de neofolclore en los años 1960 con grupos como Los Cuatro Cuartos, Los de las Condes o Las Cuatro Brujas (RIQUELME, 2012: 11). Sin embargo, Violeta Parra fue la que rescató el folclore como expresión auténtica del pueblo de las falsas imágenes proyectadas en este por las autoridades y los desarollistas, algo que pasó en el caso del neofolclore, un folclore manipulado (ibid.). Así logró por un lado salvar "una tradición amenazada" y por otro mostrar "a las capas oprimidas del pueblo su propia fuerza creativa, incluso más allá de su enajenada voluntad" (ENGELBERT, 2017 [1978]: 123).

Concretamente, la artista chilena se posicionó autónoma y críticamente ante la dominación artística y cultural y recuperó una música popular auténtica, lejos de gobiernos, consideraciones políticas, del clasismo y del elitismo, una música acunada en la memoria oral del pueblo, "oculta en el inconsciente popular", "despreciada por la cultura dominante" y enjuiciada como "bárbara" por las élites. Se encargó de transmitir y comunicar sentimientos, recuerdos, denuncias y la magia colectivos (SALAZAR \& PINTO, 1999: 148) y se convirtió así en la "voz del pueblo", la voz "de los oprimidos" (RIQUELME, 2012: 12). No solo su objetivo, sino también la manera, de la que lo procuró fueron revolucionarios, a pesar de la constante falta de financiamiento. En una primera etapa, recorrió el campo chileno en búsqueda de personajes todavía vivos y voces que le transmitirían la sabiduría popular chilena. Más tarde, decidió establecer la "Universidad nacional del folclore" en una carpa, la llamada "Carpa de la Reina" -porque estaba en la municipalidad de la Reina-, donde durante el día se daban talleres de guitarra, pintura y artesanía y por la noche tenían lugar peñas (GARCíA, 2011). Parra misma había descrito el objetivo así: "Aquí se escucharán las canciones desconocidas, las que brotan de las 
mujeres campesinas, las quejas y alegrías de los mineros, las danzas y la poesía de los isleños de Chiloé" (ibid.).

19 Aparte de esto, la Viola chilensis (PARRA, 2017 [1969]: 185), resistiendo a la "colonización mental que erosionaba a América Latina" (MILLARES, 2000: 169) con ritmos y tendencias musicales europeas y norteamericanas importadas "en detrimento de lo autóctono", reivindicó el uso de instrumentos musicales tradicionales que ya no se usaban e iban a desaparecer: la quena y el guitarrón. Según José María Arguedas, el uso de la quena en Perú se menospreciaba, ya que se consideraba un instrumento "salvaje" tocado por "sujetos marginados" y podría hasta llevar al aprisionamiento. Gracias a Violeta Parra, quien la incorporó en su mundo musical, la quena no se silenció y se volvió en un "elemento unificador" (José María Arguedas citado en ENGELBERT, 2017 [1978]: 131). Respecto al guitarrón, instrumento originalmente de salón, más tarde popular y "en extinción en el momento en que ella lo redime del olvido", el papel de la artista fue crucial (SUBERCASEAUX, STAMBUK \& LONDOÑO, 1985 [1976]: 64). Leemos en la primera canción de sus Décimas (1957-58), titulada Pa' cantar de un improviso:

"Al hablar del estrumento

diríjome al guitarrón;

con su alambre y su bordón

su sonoro es un portento.

Cinco ordenanzas le cuento,

tres de a cinco, dos de a tres,

n' el clavijero a sus pies

l'entrasta'úra 'legante;

cuatro diablitos cantantes

debe su caja tener" (Parra 1972).

Su papel central en la escena del folclore chileno, rescatando estos instrumentos del olvido y cultivando un tipo de canto caracterizado tradicionalmente masculino (como vamos a analizar en seguida), molestó a sus colegas varones.

Parece que el ambiente musical de Chile de aquella época -y ya a partir de los mediados del siglo XVIII- fue bastante segregado entre canto masculino y canto femenino (Margot Loyola citada en SUBERCASEAUX, STAMBUK \& LONDOÑO, 1985 [1976]: 46). Los cantantes varones se dedicaban al "canto a lo poeta", una expresión del arte campesino y una tradición nacional con más de 400 años de historia que todavía está presente en la parte central del país (ASTORGA, 2000: 56-64). El "canto a lo poeta" se puede definir como poesía cantada y se distingue entre el canto a lo humano, relacionado con fiestas y problemas humanos y el canto a lo divino, relacionado con rituales religiosos como los entierros, los velorios de niños o el nacimiento de Jesús (ENGELBERT, 2017 [1978]: 111). Una vertiente especial del canto a lo humano es la paya, "un duelo improvisado entre dos cantores a lo poeta" (PINOCHET COBOS, 2010: 86). En general, el canto a lo poeta puede obtener las formas de cuarteto, copla o décima espinela y procura demostrar "el virtuosismo, la habilidad y la elocuencia" del cantor (ASTORGA, 2000: 56-64). Por otro lado, las mujeres cantantes se dedicaban al canto de tonadas, cuecas, parabienes $u$ otros tipos de versos, principalmente con el objetivo de animación en fiestas y eventos. Sobre todo la tonada, como "acompañamiento de las danzas", se consideraba el "canto de las mujeres" por excelencia (Margot Loyola citada en SUBERCASEAUX, STAMBUK \& LONDOÑO, 1985 [1976]: 46). Una cantora se consideraba buena, cuando animaba a bailar hasta a los más tímidos. Ya se hace obvio cómo Violeta Parra resistió a esta dicotomía, transgrediendo las fronteras musicales impuestas. Mostrando con su propio ejemplo que 
las mujeres son capaces también de un canto virtuoso y elocuente, realizó un trabajo pionero en dos sentidos; no sólo escribió décimas, sino -mucho más importante a nivel simbólico- usó precisamente esta forma creativa considerada masculina para tejer el relato ("Pero pensándolo bien" en Parra 1972) de su vida o sea escribir su autobiografía. traspasaba las fronteras impuestas en su género a nivel profesional-artístico de dos formas más: por el tipo de viaje que a menudo emprendía y por su forma de presentarse ante el público. Los viajes femeninos en la primera mitad del siglo $\mathrm{XX}$, aunque infrecuentes, implicaban para las mujeres "un quiebre en la reclusión doméstica" y una "mayor apertura al mundo" (PINOCHET COBOS, 2010: 84). No obstante, estos viajes fueron en su mayoría viajes de caridad para las mujeres aristócratas y viajes laborales para las mujeres de las clases bajas (Pabla Ávila 2005, citada en ibid.). Violeta Parra quebró también con esta regla, realizando "una categoría de viaje celosamente reservada al género masculino: la gira" (ibid.). Su tiempo de estadía -sobre todo cuando viajaba en el extranjero- se prolongaba, según las oportunidades y las posibilidades que surgían, de unos pocos meses hasta años enteros. También en este sentido combatía el colonialismo cultural y realizaba una descentralización cultural, llevando su obra no sólo del campo a la ciudad y de la ciudad a la nación entera, sino también desde Chile a Latinoamérica (MILLARES, 2000: 171) y de ahí a las metrópolis culturales de Europa, logrando a cantar en París y exponer sus arpilleras en el Museo del Louvre, donde ningún artista plástico latinoamericano jamás había logrado exponer hasta entonces (ENGELBERT, 2017 [1978]: 111).

Asimismo, la manera de la que Violeta Parra se presentaba ante el público, con su "actitud" de rasgos "masculinos" -en realidad concentrándose en lo esencial-, aportó mucho a la liberación femenina en Chile del aquel entonces (Ángel Parra citado en EPPLE, 1987: 121-126). A esta conclusión llegó su hijo Ángel Parra, explicando que "lo que ella hizo fue tomar la guitarra y empezar a cantar sin preocuparse de los atuendos, sin maquillaje y sin adoptar una pose exterior de figura 'folclórica' al uso oficial" (ibid.). Ya se había liberado del estereotipo que "obligaba a la mujer a un permanente rol sensual y seductor" en el escenario (TORRES, 2004: 53-73) y abrió el camino para que otras cantantes sigan su ejemplo. Al mismo tiempo, tampoco adquiría la actitud humilde y modesta de otras cantoras, sino que entraba en el juego del virtuosismo procurando ser considerada en términos de igualdad con sus colegas masculinos. En sus presentaciones traía características tanto masculinas como femeninas y sobre todo individuales, logrando más que todo una intimidad y una cercanía con su público únicas (PINOCHET COBOS, 2010: 87-88).

\section{Los versos de Violeta Parra como espacio de enunciación múltiple y empoderamiento del sujeto femenino}

Después de haber expuesto cómo la Viola admirable (PARRA, 2017 [1969]: 184) rompió con las normas sociales y artísticas de su época, logrando salir de la posición marginal que le otorgaban, vamos a analizar cómo representó la subalternización y la lucha contra esta en su obra escrita -sin querer menospreciar con eso el resto de su obra artística-. Concretamente vamos a examinar como se describen en sus versos las varias opresiones que imponían las estructuras sociales hegemónicas en su tiempo, como también la lucha de enunciación y empoderamiento del sujeto femenino. 


\section{Los versos como espacio de enunciación múltiple} una relación dialógica ${ }^{14} \mathrm{y}$ nunca conluida con el pasado, ya que las opresiones persiguen de modo muy parecido. Santiago está penando con penas muy parecidas a las que tenía la Araucanía ("Santiago, penando estás" y "Arauco tiene una pena" en ENGELBERT, 2017 [1978]: 174-176, 178-180), aunque el colonialismo ahora es de otro tipo; ya no se trata del colonialismo español de la Conquista, pero el objetivo es el mismo -el oro-, tal como el medio para conseguirlo: la violencia. Ahora oro cobra el hortelano/ que va sembrando rencor (versos 5-6), así como el conquistador buscaba antes montañas de oro (versos 9-10). A Santiago le derrumban el cuerpo y su alma sale a rodar (versos 33-34), de forma parecida que corría la sangre del indio, ya que le iban a quitar su tierra (versos 15,17). Tampoco los niños disfrutan de una infancia, acostumbrados como están a la violencia: el niño me causa espanto/ ayer jugaba a la ronda/ hoy juega con un fusil (versos 15, 17, 18) ${ }^{15}$. Peor aún, ya no son los españoles/los que les hacen llorar,/ hoy son los propios chilenos/los que les quitan su pan (versos 38-41).

¿quiénes son estos chilenos que quitan? y ¿a quiénes hacen llorar? La respuesta la ofrece Violeta Parra en otros versos, donde critica los rasgos del sistema capitalista, lo que se amplió en todo el globo como nueva forma de colonialismo. ${ }^{16}$ Concretamente cuestiona el clasismo que segrega a los ricos de los pobres y hace que los primeros exploten a los segundos, el racismo que resulta en la opresión continua de los indígenas y el sexismo que permite que las mujeres sufran por ser mujeres. En su canción Al centro de la injusticia (ENGELBERT, 2017 [1978]: 196-198) leemos (versos 5-12):

Al medio están los valles con sus verdores

donde se multiplican los pobladores,

cada familia tiene muchos chiquillos,

con su miseria viven en conventillos.

Claro que algunos viven acomodados,

pero eso con la sangre del degollado.

Delante del escudo más arrogante

la agricultura tiene su interrogante.

\section{2) también leemos:}

En este mundo moderno, qué sabe el pobre de queso

(...)

pero bien sé que el burgués se pit' al pobre verdejo. 

¡Válgame Dios cómo están
Todos los pobres cristianos
En este mundo inhumano
Partidos mita' a mita'!
Del rico es esta maldad,
lo digo muy monmovi'a!

No obstante, la cantautora no para ahí, pues nombra concretamente como fuentes de opresión al capital y sus instituciones (bancos), al estado con los políticos y a la iglesia con sus curas. Característicos son los versos de su canción Yo canto la diferencia (ENGELBERT, 2017 [1978]: 146-150), con los que condena -con notable ironía- la hipocresía de los políticos (versos 36-41)
Afirmo, Señor Ministro,
que se murió la verdad.
Hoy día se jura en falso
por puro gusto nomás.
Engañan al inocente
sin ni una necesidad.

y de los considerados representantes de Dios en tierra (versos 43-53):
Ahí pasa el señor vicario
con su balabra bendita.
¿Podría su Santidad
oirme una palabrita?
Los niños andan con hambre,
les dan una medallita
o bien una banderita.
Por eso, su Señorida,
dice el sabio Salomón,
hay descontento en el cielo,
en Chuqui y en Concepción.

32 Los, a los que hacen llorar, son el pueblo o sea la gente de las clases bajas de la sociedad que tiene que soportar y sufrir por las muchas tristezas a lavar ("La lavandera" en ENGELBERT, 2017 [1978]: 228-230): la pobreza, la injusticia, la explotación. Además, es la gente a la que no le está permitido "hablar", es decir resistir y luchar para que su situación cambie y se mejore o, en el caso que logre hablar, su voz no se escucha o se malinterpreta. Son las personas subalternizadas, sean los campesinos, los mineros, los indios o las mujeres.

Su silenciamiento se encuentra por ejemplo en las canciones "Porque los pobres no tienen", versos 8-10 y 12-13, y "Arauco tiene una pena", versos 45-48, (ENGELBERT, 2017

[1978]: 152-154, 178-180):

porque los pobres no tienen

adonde volver la voz,

la vuelven hacia los cielos

ya que su hermano no escucha

la voz de su corazón

340

pero el quejido del indio

¿por qué no se escuchará,

aunque resuene en la tumba

la voz de Caupolicán? 
Los versos siguientes de la canción “Arriba quemando el sol”, versos 50-53, (ENGELBERT, 2017 [1978]: 142-144) atestiguan de las veces que el "no" se malinterpreta con intención como "sí", resultando en un silenciamiento semejante:

$$
\begin{aligned}
& \text { Me volví para Santiago } \\
& \text { sin comprender el color } \\
& \text { con que pintan la noticia, } \\
& \text { cuando el pobre dice no. }
\end{aligned}
$$

Ya que la reacción y la resistencia de la gente oprimida se imposibilita -sea porque no se le permite "hablar" o porque, una vez hablado, su voz no se percibe o se silencia malinterpretada-, la Viola piadosa se encarga de darle voz; no por piedad, sino porque a ella también se le intentó silenciar y subalternizar y sabe que su arte es su arma de batalla: reclamo porque a la fosa/van las penas del mendigo ("Mas van pasando los años", versos 31-34 en PARRA, 1972).

En este mismo sentido advierte en "Yo canto la diferencia", versos 66-67 y 71-72 (ENGELBERT, 2017 [1978]: 87-90 y 1-7):

Si yo levanto mi grito no es tan solo por gritar. Perdóneme el auditorio, si ofende mi claridad. Yo canto a la chillaneja, si tego que decir algo, y no tomo la guitarra por conseguir un aplauso. Yo canto la diferencia que hay de lo cierto a lo falso. De lo contrario no canto.

0 , en los casos donde matan a sangre fría a quien defensa no tiene:

yo pido que se propale por toda la población que el "león" es un sanguinario en toda generación, sí.

Por suerte tengo guitarra para llorar mi dolor.

Estos últimos versos, tomados de "La carta" (versos 33-38 en ENGELBERT, 2017 [1978]: 162-164) son característicos de la instrumentalización del arte como medio de resistencia y empoderamiento. ${ }^{17}$ Aquí Violeta Parra usa su canción (y no solo su guitarra) con un objetivo triple: primero, llorar su dolor, segundo, informar al público sobre la encarcelación arbitraria de su hermano quien no tiene otra defensa y tercero, tomar acción, reclamando la injusticia y buscando alianzas en su lucha. En otras canciones lo hace de manera aún más explícita, convocando por ejemplo a los héroes mapuches ${ }^{18}$ a una revolución o soñando y predicando un mundo al revés ("Por el mundo al revés" en ENGELBERT, 2017 [1978]: 111-113). Si ve las estrellas en el suelo, el mar sin hondura, un juez condena'o, un ciego viendo, un cura de penitente, la mujer sembrando, el demonio confesa'o o un sordo oyendo canciones, no es porque fuera loca-como la acusaron con el pretexto también de esta canción-, sino porque procura deformar, ironizar y deconstruir todas las normas de pensamiento, torcer las identidades impuestas por las estructuras hegemónicas y precisamente retorcer el mundo (KROLL, 2007: 13) para poder después construir otro. 


\section{El empoderamiento del sujeto femenino; La lechera y La jardinera}

Especial lugar entre la gente oprimida para la que escribe Violeta Parra tienen las mujeres, las que parecen preocuparla mucho. Con canciones dedicadas enteras a ellas, sus problemas y su realidad difícil o con versos incluidos en creaciones de focalidad distinta, la artista chilena no pudo dejar callada esta verdad que le quema el alma. Así encontramos canciones tituladas La jardinera, La lechera, La lavandera como también los personajes de Valentina ${ }^{19}$, de Luisa, quien espera maternidad pero no tiene casa, ni una vela, ni un pañal ("Yo canto la diferencia", versos 66-67 y 71-72 en ENGELBERT, 2017 [1978]: 146-150) o de la isleña, la madre del indio, la hermana o la compañera, pelando a un lado papas ("Según el favor del viento", versos 21-24 en ENGELBERT, 2017 [1978]: 156-160).

41 A continuación, para reforzar nuestro itinerario argumentativo y exponer la ruptura del silencio y el empoderamiento del sujeto femenino (que deja de ser subalterno) en la escritura de Violeta Parra, vamos a analizar sus canciones La lechera y La jardinera (ENGELBERT,2017 [1978]: 140, 138). Examinaremos cómo el lenguaje sirve para la expressión de un sujeto y su sujetividad, es decir su conciencia, (SCHMITZ, 1998 [1997]: 13) y cómo este lenguaje se forma en los márgenes o sea "en la frontera creativa", ya que las conciencias descritas se forman también en los márgenes (MORRIS, 1994: 4-5). Más aún, se trata de las conciencias de sujetos femeninos que hablan, logrando así salir de su posición marginal, aunque no pareciera así a primera vista.

\section{La lechera}

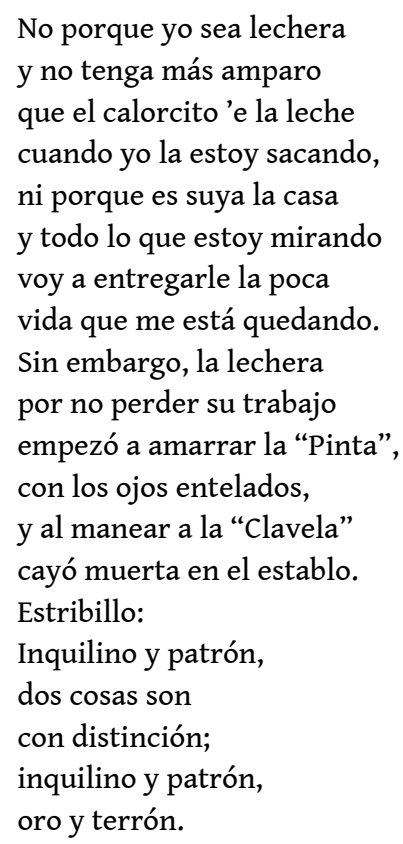

Esta canción de Violeta Parra es considerada la primera con un compromiso político explícito (ENGELBERT, 2017 [1978]: 128), sin embargo no es más política que otras canciones $\mathrm{u}$ otros versos suyos, como ya hemos visto y vamos a ver en seguida. El sujeto aquí verbaliza los prejuicios respecto a las opresiones sufridas: la opresión de clase, de género, de edad y los fenómenos socio-económicos conectados con estas. El clasismo se 
exhibe por la distinción entre ella y sus "patrones": ella es una simple lechera, pobre y sin propiedad, mientras que a sus patrones les pertenece la casa y todo lo que está mirando la hablante, en el momento, en el que habla. Por lo contrario, ella, siendo pobre, el único calor que puede sentir es el de la leche que saca.

La lechera como mujer subalternizada intenta resistir, pero al final muere. El cambio de la persona -de la primera en la primer estrofa a la tercera en la segunda estrofa de la canción- acentúa la falla y la desilusión. La muerte que anula las palabras previas de la lechera -por un lado porque esta misma es el silencio final y por otro porque la persona no tendrá la oportunidad de poner en práctica sus declaraciones- podría llevar a la conclusión que la mujer no habló y su esfuerzo a salir de su posición marginal y empoderarse falló. No compartimos tal conclusión y explicaremos como, desde nuestro punto de vista, la lechera logró hablar: primero, lo hizo porque es con sus palabras que empieza la canción. Además, a sus palabras se les concede más espacio que al acontecimiento de su muerte; sus palabras ocupan ocho versos (1-8), mientras que su debilitación y su muerte se describen en seis (9-14). Más aún, el sujeto culmina su acción de resistencia declarando que no va a entregarles (a sus patrones y consecuentemente a la clase alta dominante) su vida, por poca que le quedara. No solo el carácter de advertencia, sino también el hecho de que al final estas fueron sus últimas palabras, hacen de sus palabras un acto verbal (VOLOSHINOV/ BAKHTIN, 1994 [1973]: 59) que demuestra un sujeto empoderado y sobre todo libre.

\section{La jardinera}

Para olvidarme de ti

voy a cultivar la tierra, en ella espero encontrar remedio para mis penas. Aquí plantaré el rosal de las espinas más gruesas, tendré lista la corona para cuando en mi te mueras. Creciendo irán poco a poco los alegres pensamientos, cuando ya estén florecidos irá lejos tu recuerdo. De la flor de la amapola seré su mejor amiga, la pondré bajo la almohada para dormirme tranquila. Cogollo de toronjil, cuando me aumentan las penas, las flores de mi jardín han de ser mis enfermeras. Y si acaso yo me ausento antes que tú te arrepientas, heredarás estas flores, ven a curarte con ellas. Estribillo:

Para mi tristeza violeta azul, clavelina roja pa' mi pasión, y para saber si me corresponde deshojo un blanco manzanillón: si me quiere mucho, poquito, nada, 
tranquilo queda mi corazón.

A primera vista, la jardinera aquí llora y lleva luto por un amor perdido. Amamantada en el seno de una sociedad patriarcal que espera de las mujeres que sean buenas esposas y madres, la jardinera no puede, sino necesitar remedios y enfermeras para su fracaso. Sin embargo, también aquí una lectura más cercana nos convence de otra realidad. Las flores, sus efectos y sus substancias que le ofrecerán remedio de sus penas son producto de sus propias manos: ella las plantará y ella las cultivará; serán las flores de su jardín. Y no sólo va a curarse a sí misma por medio de sus propias fuerzas, sino que también está segura del resultado feliz: el recuerdo del hombre querido irá lejos y se va a morir en ella. Más aún, está tan segura de que va a superar su sufrimiento y a él, que hasta considera posible que él regrese arrepentido, pero sin encontrarla; ella ya se habrá ido, será ausente. Y como para eliminar la menor duda -de que así pasen las cosas- hasta del público más escéptico, proclama que le dejará al hombre como herencia las mismas flores para que él también se cure; ya sin ningún rencor ni amargura, lo ayudará a él también a superar sus penas. $\mathrm{Al}$ fin y al cabo le va a dar lo mismo si él la quiere mucho, poquito o nada, ya que su corazón quedará tranquilo. Se nos presenta entonces una mujer fuerte, dueña de sí misma y su destino, en todo su esplendor.

\section{Conclusiones}

A pesar de los esfuerzos por subalternizar y silenciarla, presentándola como persona loca o censurándola de varias maneras, Violeta Parra se mostró como sujeto empoderado quebrando con los estereotipos de su época sobre la identidad femenina y la creación artística, transgrediendo fronteras, salvando instrumentos tradiccionales del olvido, creando formas artísticas nuevas, reviviendo el folclore y descentralizando la cultura chilena. En su escritura encontramos elementos sumamente políticos, no porque se trate de canciones de compromiso político explícito en términos de alineamiento con cierta ideología, sino porque sus versos -sus Décimas autobiográficas incluidas- representan un espacio de enunciación múltiple, donde se tematizan las varias opresiones y el empoderamiento (la salida de su posición marginal) del sujeto femenino. Se trata de una forma de activismo artístico que procura por un lado la anhelada justicia social a nivel tanto local como global y por otro lado la liberación femenina. Es una escritura que con gusto vuelve el mundo al revés para combatir el silenciamiento propio, como también del indígena, del pobre o de la mujer, que persigue hasta el día de hoy por estructuras neocoloniales y sociedades patriarcales. Y sobre todo, es una escritura que nace de la fascinación ante el fenómeno del arte, como también de la afirmación profunda del arte (KROLL, 2018: 18) y de la vida misma. ¿Qué forma más clara podría usar la artista chilena para expresarlas que su canción Gracias a la vida? (ENGELBERT, 2017: 224-226)

\section{BIBLIOGRAFÍA}




\section{BIBLIOGRAFÍA}

ASTORGA, Francisco (2000), “El canto a lo poeta”, en Cristián Guerra Rojas, Vol. 54, Núm.194.

Revista Musical Chilena, Universidad de Chile, Facultad de Artes. Pp 56-64: https://

revistamusicalchilena.uchile.cl/index.php/RMCH/article/view/12584/12889

BHABHA, Homi K. (1994), The Location of Culture, Routledge, London.

CASTRO Varela, María do Mar/Dhawan, Nikita (2015), “Gayatri Chakravorty Spivak - Marxistisch-

feministische Dekonstruktion", en Rainer Winter Postkoloniale Theorie, Eine kritishe Einführung, 2.

Komplett überarbeitete und erweiterte Auflage, transcript Verlag, Bielefeld.

COMBAHEE River Collective [2015 (1977)], “A Black Feminist Statement”, en Cherríe Moraga \&

Gloria Anzaldúa, This Bridge Called My Back; writings by radical women of color, 4th Edition, SUNY

Press, Albany.

COOPPAN, Vilashini (2005), “The Ruins of Empire: the National and Global Politics of America's

Return to Rome", en Ania Loomba et. al. Postcolonial Studies and Beyond, Duke University Press, Durham.

DIRLIK, Arif (1997), "The Local in the Global”, en The Postcolonial Aura: Third World Criticism in the Age of Global Capitalism, Westview Press, Boulder.

ENGELBERT, Manfred [2017(1978)], Violeta Parra, Lieder aus Chile/ Canciones de Chile, Antología Bilingüe, Edición 3a , Vervuert, Frankfurt am Main, e Iberoamericana, Madrid.

EPPLE, Juan Armando (1987), “Entretiene avec Angel Parra, Preguntas por Violeta Parra”, en № 48, Caravelle, Cahiers du monde hispanique et luso-brésilien, Presses Universitaires du Midi.

ESTEVA, Gustavo y Madhu Suri Prakash (1998), Grassroots Post-Modernism:

Remaking the Soil of Cultures, Zed Books Ltd, London.

FREIRE, Paolo [2017 (1970)], Pedagogy of the Oppressed, 30th Anniversary Edition (trad. por Myra Bergman Ramos), Bloomsbury Publishing, London.

GARCíA, Gabriela (2011), “En busca de la carpa de Violeta Parra”, en La tercera, http://

diario.latercera.com/edicionimpresa/en-busca-de-la-carpa-de-violeta-parra/ Publicado en 7 de agosto de 2011, última consulta en 12 de mayo de 2018.

GONZÁLEZ, Juan Pablo, Ohlsen, Oscar y Rolle, Caludio (2009), Historia social e la música popular en Chile, 1950-1970, Universidad Católica de Chile, Santiago de Chile.

GUHA, Ranajit (1982), “On Some Aspects of the Historiography of Colonial India”, en Ranajit Guha, Subaltern Studies I: Writings on South Asian History and Society, Oxford University Press, New Delhi.

GUSFIELD, Joseph (1994), "La reflexividad de los movimientos sociales”, en Enrique Laraña y Joseph Gusfield, Los nuevos movimientos sociales: de la ideología a la identidad, Centro de Investigaciones Sociológicas (CIS), Madrid.

HOLQUIST, Michael (2002), Dialogism: Bakhtin and his World. 2nd Edition, Routledge. London \& New York.

ноокs, bell (1990), Yearning. Race, Gender and Cultural Politics, South End

Press, Boston.

ноокs, bell (1989), Talking Back, South End Press, Boston. 
IBÁRRA Cáceres, Anaeli (2016), "La relación arte-política en Cuba: entre el Silencio y el susurro. El arte como el lugar de acción y repolitización de la vida", en Arte y Políticas de la Identidad, Vol. 13, Revista Arte y Políticas de la Identidad, Publicaciones de la Universidad de Murcia, Murcia: https://revistas.um.es/reapi/article/view/250931/190421

KRISTEVA, Julia (1978), Die Revolution der poetischen Sprache (trad. por Reinold Werner), Suhrkamp Verlag. Frankfurt am Main.

KRISTEVA, Julia (2016 [1998]), „Vorwort“ en Die Zukunft einer Revolte, Brandes \& Apsel Verlag, Frankfurt am Main.

KROLL, Renate (1999), „Was können Gender Studies heute leisten? Zu Versionen der Subversion und (weiblicher) Subjektkonstitution“, en Renate Kroll \& Margarete Zimmerman, Gender Studies in den romanischen Literaturen: Revisionen, Subversionen, Tomo I, dipa-Verlag, Frankfurt am Main.

KROLL, Renate (2007), Blicke die ich sage. Frida Kahlo, Das Mal- und Tagebuch, Dietrich Reimer Verlag, Berlin.

KROLL, Renate (2018), „Kunsttheorie, die nicht eine ist: Zwischen Manifestation, Reflexion und Konfession“, en Renate Kroll y Susanne Gramatzki Künstlerinnen schreiben, Ausgewählte Beiträge zur Kunsttheorie aus drei Jahrhunderten, Dietrich Reimer Verlag, Berlin. LANDRY Donna y Maclean, Gerald (1995[1985]), "Subaltern Studies, Deconstructing Historiography”, en Donna Landry y Gerald Maclean, The Spivak Reader, Routledge, New York/ London.

LARAÑA, Enrique (1999), La construcción de los movimientos sociales, Alianza Editorial, Madrid. LOomBA, Ania et. al (2005), “Beyond What? An Introduction”, en Ania Loomba et. al. Postcolonial Studies and Beyond, Duke University Press, Durham.

LORDE, Audre (2007[1981]), “An Interview: Audre Lorde and Adrienne Rich”, en Sister Outsider: Essays and Speeches by Audre Lorde, Crossing Press, Nueva York.

Mignolo, Walter D (2000), Local Histories/ Global Designs, Coloniality, Subaltern Knowledges and Border Thinking, Princeton University Press, Princeton, New Jersey.

MIGUEL ÁLVAREZ, Ana de (2005), “La construcción de un marco feminista de interpretación: la violencia de género", en № 18, Cuadernos de Trabajo Social, Universidad Complutense de Madrid, Madrid: https://dialnet.unirioja.es/servlet/articulo?codigo=1314215

MILLARES, Selena (2000), “Geografías del Edén: La poesía trovadoresca de Violeta Parra”, en Centro de Estudios de Literatura Chilena, $\mathrm{N}^{\circ} 1$, Anales de Literatura Chilena, Pontificia Universidad Católica de Chile, Santiago de Chile.

MORAGA, Cherríe \& Anzaldúa, Gloria (2015 [1981]), This Bridge Called My Back; writings by radical women of color, 4th Edition, SUNY Press, Albany.

MORRIS, Pam (1994), “Introduction”, en The Bakhtin Reader, Edward Arnold Ltd, London.

MORRIS, Rosalind C (2010), "Introduction", en Rosalind C. Morris, Can the

Subaltern Speak? Reflections on the History of an Idea, Columbia University Press, New York.

PARRA Ángel (2006), Violeta se fue a los cielos, Catalonia, Santiago de Chile.

PARRA, Nicanor [2017 (1969)], “Defensa de Violeta Parra”, en Matías Rivas, El último apaga la luz, Obra selecta, Lumen, España. 
PARRA, Violeta [1972 (1970)], Décimas - Autobiografía en versos chilenos, $2^{\mathrm{a}}$ edición, Ediciones Nueva Universidad-Universidad Católica de Chile, Santiago de Chile, consultado en: https:// www.cancioneros.com/nd/2722/0/decimas-autobiografia-en-versos-chilenos-libro-violeta-parra. PECHEY, Graham (2007), Mikhail Bakhtin, The Word in the World, Routledge, New York.

PINOCHET COBOS, Carla (2010), "Violeta Parra: tensiones y transgresiones de una mujer popular de mediados del siglo XX”, en Cristián Guerra Rojas, Vol. 64, No 213, Revista Musical Chilena, Universidad de Chile, Facultad de Artes: https://revistamusicalchilena.uchile.cl/index.php/ $\mathrm{RMCH} /$ article/view/1717/1587

PISANO, Margarita (1996[1995]), “Las trampas del sistema, Transgredir el hecho

cultural y simbolizarnos como humanas", en Sandra Lidid Un cierto desparpajo, ediciones Número Crítico, Chile.

POTTHAST, Barbara (2009), „Gender, Gesellschaft und Politik in Lateinamerika - Eine

historiographische Bilanz“, en Delia Gonzáles de Reufels, Von fernen Frauen: Beiträge zu

lateinamerikanischen Frauen und Geschlechtergeschichte, Verlag Hans-Dieter Heinz, Stuttgart.

POTTHAST, Barbara (2010), Von Müttern und Machos: eine Geschichte der Frauen Lateinamerikas, 2., überarbeitete Auflage, Hammer, Wuppertal.

RIBEIRo Dos Santos, Renata (2015), “ ¿Meter el arte en el mundo? Sociedad,

conducta y arte en las propuestas de Tonia Bruguera", en Arte y políticas de identidad, Vol. 13, Publicaciones de la Universidad de Murcia, Murcia.

RICHARD, Nelly (1994), La insubordinación de los signos, Cambio político,

transformaciones culturales y poéticas de la crisis, Editorial Cuarto Propio, Santiago de Chile.

RIQUELME, Natalia T (2012), "Marco histórico del desenvolvimiento de Violeta Parra como sujeta subalterna en el escenario socio-cultural chileno en el período 1932-1967”, en Centro Telúrico de Investigaciones Teóricas № 3, CISMA: Revista del Centro Telúrico de Investigaciones Teóricas, Chile: https://dialnet.unirioja.es/servlet/articulo?codigo $=4482858$

SALAZAR, Gabriel y Pinto, Julio (1999), Historia Contemporánea de Chile, Tomo V, Ediciones LOM, Santiago de Chile.

SCHMITZ, Bettina (1998 [1997]), Arbeit an den Grenzen der Sprache, Julia Kristeva, Ulrike Helmer Verlag, Königstein/ Taunus.

SIEBER, Cornelia (2005), Die Gegenwart im Plural, Postmoderne/postkoloniale

Strategien in neueren Lateinamerikadiskursen, Vervuert, Frankfurt am Main.

SIEBER, Cornelia (2012), „Der ,dritte Raum des Aussprechens' - Hybridität -

Minderheitendifferenz, Homi Bhaba: „The Location of Culture““”, en Julia Reuter/ Alexandra Karentzos, Schlüsselwerke der Postcolonial Studies, Springer, Wiesbaden.

SPIVAK, Gayatri Chakravorty (1985), "The Rani of Sirmur: an Essay in Reading the Archives", en Vol. 24, $\mathrm{N}^{\circ}$ 3, History and Theory, consultado en: http://artsites.ucsc.edu/sdaniel/230/ spivak_readingarchive.pdf SPIVAK, Gayatri Chakravorty (1999), A Critique of Postcolonial Reason, Towards A History of the Vanishing Present, Seagull, Calcutta/ New Delhi.

SPIVAK, Gayatri Chakravorty (2010 [1999]), “Can the Subaltern Speak?” en Rosalind C. Morris, Can the Subaltern Speak? Reflections on the History of an Idea, Columbia University Press, New York. 
SPIVAK, Gayatry, Chakravorty (2010), “In Response, Looking back, looking forward”, en Rosalind C. Morris, Can the Subaltern Speak? Reflections on the History of an Idea, Columbia University Press, New York.

SUBERCASEAUX, Bernardo y Londoño, Jaime (1976), Gracias a la vida - Violeta

Parra, testimonio, Editorial Galerna, Buenos Aires.

SUBERCASEAUX, Bernardo, Stambuk, Patricia y Londoño, Jaime [1985 (1976)]

Gracias a la vida - Violeta Parra, testimonio, $4^{\text {a }}$ edición, Editorial Galerna, Buenos Aires.

TALPADE Mohanty, Chandra (1991), "Introduction, Cartographies of Struggle: Third World Women and the Politics of Feminism", en Chandra Talpade Mohanty, Ann Russo y Lourdes Torres, Third World Women and the Politics of Feminism, Indiana University Press, Bloomington and Indianapolis.

TALPADE Mohanty, Chandra (2003), ““'Under Western Eyes” Revisited: Feminist

Solidarity through Anticapitalist Struggles", en Feminism Without Borders: Decolonizing Theory, Practicing Solidarity, Duke University Press, Durham.

TORRES, Rodrigo (2004), “Cantar la diferencia, Violeta Parra y la canción chilena”, en Cristián Guerra Rojas, Vol. 58, № 201, Revista Musical Chilena, Universidad de Chile, Facultad de Artes: https://revistamusicalchilena.uchile.cl/index.php/RMCH/article/view/12448/12761

VICUÑA, Cecilia (2007), “Violeta Parra o Violeta Vid”, en Sabor a mí, Ediciones Universidad Diego Portales. Santiago de Chile.

voloshinov, V.N./ Bakhtin, M (1994 [1973]), “Marxism and the Philosophy of

Language" (trad. por L. Matejka \& I. R. Titunik), en Pam Morris, Language as Dialogic Interaction, The Bakhtin Reader, Edward Arnold Ltd, London.

WESLING, Donald (2003), Bakhtin and the Social Moorings of Poetry, Bucknell University Press, London.

ZEILINGER, Irene (2004), „Globale Brutalität, Globalisierung und Gewalt gegen Frauen an der mexikanisch-amerikanischen Grenze“, en Claudia Thallmeyer/ Karin Eckert, Sexismen und Rassismen: Lateinamerikanerinnen zwischen Alter und Neuer Welt, Promedia Druck- und Verlagsgesellschaft, Wien.

Páginas web:

"memoriachilena: Biblioteca Nacional de Chile":

http://www.memoriachilena.cl/602/w3-article-98197.html

"Archivo Chile":

https://www.archivochile.com/

\section{NOTAS}

1. Gabriela Mistral no fue menos subalternizada por la malinterpretación de su obra, sobre todo después de su muerte, pero este sería el tema de otro trabajo.

2. La construcción de la otredad ("othering") por el discurso hegemónico sirve como instrumento de opresión. Basándose en un pensamiento binario, se refiere a los procesos de exclusión, devaluación o apropiación destructiva de lo que no corresponde con el ideal según el punto de vista hegemónico. Al Otro se le proporcionan entonces características que la cultura hegemónica 
excluye, como la inferioridad, la irracionalidad, la ingenuidad o el primitivismo. Así se construyen estructuras de poder que no solo permiten la dominación (política, económica, social), sino que la hacen sumamente efectiva. El objetivo entonces es la superación de la otredad, lo que deslegitimaría la superioridad de lo hegemónico (cf. Spivak 1985, Sieber 2005).

3. El silenciamiento, como afirmación de la no-existencia, lleva para Gayatri Chakravorty Spivak a resultados semejantes al aniquilamiento físico (cf. Spivak 2010 [1999]: 61).

4. Lo "subalterno", significando lo no-hegemónico y lo marginal, se refiere a las exclusiones, omisiones y desfiguraciones del discurso hegemónico y, más que una identidad, se entiende como una posición (en tránsito) y una diferencia (otredad). A nivel político-social designa a grupos sociales que no forman élites (no hegemónicos) y emerge como producto de una red de tendencias distintas y hasta contradictorias. Entonces, desde el punto de vista de los estudios subalternos, no solo se cuestiona el ejercicio del poder cultural y social por parte de grupos hegemónicos, sino que se promueve la revisión de los modelos de percepción, pensamiento y representación (cf. Sieber 2005, Castro Varela, María do Mar y Dhawan 2015, Guha 1982, Spivak 1999, Landry y Maclean 1995 [1985], Morris 2010).

5. Había contraído matrimonio dos veces, la primera en 1937 con Luis Cereceda y la segunda en 1950 con Luis

Arce (Engelbert 2017 [1978] y http://www.memoriachilena.cl/602/w3-article-98197.html )

6. La voz libertadora se entiende como aquella voz que permite a la gente oprimida el tránsito desde el silencio hacia un lenguaje que facilite la vida y la evolución. Se trata del cruzar las fronteras de la articulación, lo que implica la subjetivación (el paso de llegar a ser sujeto, tomando conciencia de si mism@ y autodefiniéndose) y posibilita la resistencia o sea las luchas contra-hegemónicas. La voz libertadora resulta así fuente y al mismo tiempo resultado de una serie de procesos libertadores que amenazan el statu quo (hooks 1989, 1991, Freire 2017 [1970], Talpade Mohanty 1991).

7. Las fronteras, también signalizadas como márgenes, representan, en vez de un sitio de deprivación, un espacio de posibilidad radical y resistencia. Son estos márgenes los que vienen a reemplazar el centro del discurso hegemónico, ofreciendo miradas contra-hegemónicas y así mucho más cercanas a la realidad global y sobre todo subalterna. La función de los márgenes como lugar de resistencia es imprescindible para las comunidades oprimidas, explotadas y colonizadas. Si los márgenes se vieran exclusivamente como lugar de desesperación, esto resultaría en un sentimiento de frustración y consecuentemente de desempoderamiento, en el que la creatividad, la imaginación y la libertad colectivas se destruirían por mentes colonizadas. Los márgenes pueden ser también entendidos como el lugar entre dos maneras de ser, donde la primera quiere resistir completamente y la segunda quiere aceptarlo todo completamente. Estar en los márgenes también puede significar distinguir entre la marginalidad impuesta por estructuras opresivas y aquel tipo de marginalidad que alguien escoge como espacio de lucha, es decir como espacio de apertura radical y posibilidad. Además, este espacio de resistencia se forma constantemente dentro de una cultura de oposición, lo que es la respuesta crítica a la dominación. Por eso la lucha contra la colonización es una lucha por la libertad y la libertad de expresión y no empieza necesariamente contra el colonizador, sino contra cada fuerza opresiva, sea la comunidad colonizada o la familia (cf. bell hooks 1990: 150-151, Audre Lorde 2007 [1981]: 106, Moraga/Anzaldúa 2015 [1981]).

8. Se trata de una dinámica de los márgenes como ella fue entendida y descrita más tarde por la compatriota de Violeta Parra y crítica de la cultura, Nelly Richard. Puede ser que Richard desarolló su teoría para la "nueva escena" de la década de los 1980, pero no se puede negar ni la postura enunciativa de la escritura de Violeta Parra, ni tampoco su papel como un nuevo tipo de crítica social que buscaba desorganizar las reglas de composición del orden que le dan sistematicidad al poder. Violeta Parra tenía y reproducía en su obra un pensamiento fronterizo o doblemente crítico que 
socavaba las fronteras construidas y generaba procesos nuevos, siendo el mismo en evolución, sin querer llegar a ser hegemónico (cf. Sieber 2005, Richard 1994, Mignolo 2000).

9. A consecuencia de la percepción de lo subalterno como una posición y además una posición no hegemónica, se pone en evidencia la invisibilidad y el silenciamiento como condiciones muchas veces asociadas con este. Se podría decir que la invisibilidad de la persona subalterna es producto de su silenciamiento impuesto. Sin embargo, una vez que se rompa el silencio y se logre la articulación la persona deja, según Spivak, de ser subalterna. La ruptura del silencio representa un acto de resistencia y es entonces cuando las personas se vuelven sujetos. Reconocer su sujetización es, a su vez, un gesto político que no se debe menospreciar, ya que precisamente este se suprime por las políticas hegemónicas de exclusión (cf. Spivak 1999 \& 2010, Morris, 2010).

10. Los conquistadores habían llevado al "nuevo" mundo sus estructuras sociales patriarcales y, con estas, una consideración tradicional del papel de los géneros, según la cual el lugar "natural" de las mujeres era la casa, en donde ellas tenían que restringirse. Sobre todo se subrayaba su papel de buenas madres y se les atribuían como virtudes máximas el altruismo, el espíritu de sacrificio, la reserva, la paciencia, la autodegradación y el servilismo. En la imposición y promoción de estas virtudes la religión católica tocó un papel fundamental, presentando a la Virgen María (mater dolorosa) y a las santas como ejemplo a imitar. El cambio de las condiciones de género en Latinoamérica pudo llevarse a cabo solo de manera lenta y parcial durante la primera mitad del siglo XX, pero no consiguió ningún distanciamiento verdadero del sistema patriarcal, así que los esquemas patriarcales persisten hasta el día de hoy (cf. Potthast, 2009 y 2010).

11. Si nos referimos a las distintas formas con las que Nicanor Parra nombró a su hermana en su poema "Defensa de Violeta Parra", no es porque creamos que necesite ser defendida, sino más bien en el sentido shakespeareano ("what shall i call thee?"), lo que compartieron poetas como Pablo Neruda (llamándola Santa Violeta y ciruela salvaje en su "Elegía para cantar", parte del prólogo de las Décimas, Parra 1972) o Cecilia Vicuña (nombrándola Viola amada en Vicuña 2007).

12. Sobre esta capacidad de la poesía de articular la voluntad de una voluntad libre escribió Kristeva (Kristeva 2016 [1998]: 12).

13. El enunciado, de corte bajtiano, se entiende aquí como una interacción verbal que se determina por las formas discursivas de la interacción social, la que -a su vez- se precisa por las estructuras sociales y políticas. Está relacionado con la producción de significado que se entiende como un proceso y una evolución en constante negociación y diálogo con el pasado, el futuro y los enunciados situados en estos. En esto en enunciado bajtiano se relaciona con el proceso de significación de Julia Kristeva y el tercer espacio de enunciación de Hommi Bhabha. (cf Sieber 2012 \& 2005, Morris 1994, Wesling 2003, Bhabha 1994, Kristeva 1978, Schmitz 1998 [1997]).

14. También en términos bajtianos (cf Pechey 2007: 1, Wesling 2003: 22, 31, 34, 39, 41. y Holquist 2002: 67).

15. También en sus Décimas escribe de la infancia y la inocencia perdidas: "los niños ya no son niños,/ son pájaros espantados" ("Por ese tiempo, el destino" en Parra 1972).

16. El capitalismo y la aplicación de los términos de mercado en todos los sectores de la vida, es decir la ubicación de los valores empresariales en la base de los sistemas sociopolíticos, son características principales del mundo globalizado. Sus políticas neoliberales consisten en los flujos transnacionales de capital, bienes y personas, una división del trabajo a nivel internacional compleja, la aceptación de los riesgos como parte integral de la vida moderna, y la conexión internacional de redes de información, de movimientos políticos e instituciones. Así que la globalización se puede entender por un lado como un proceso de decolonización incesante reflejando la heterogeneidad creciente del mundo, pero por otro lado, como una reformulación colonial por medio de un capitalismo global. Esta decolonización parcial no significa otra cosa que un nuevo orden global que establece una hegemonía neoliberal como forma de neocolonialismo. La globalización llega a significar entonces la prolongación del proyecto 
imperialista del Occidente, hoy liderado por la intensificación del imperialismo norteamericano (cf. Vilashini Cooppan 2005, Ania Loomba et. al. 2005, Zeilinger 2004).

17. El "arte político" llegó a ser un concepto que "perdió toda la fuerza y la validez que en algún momento lo caracterizó". En esto aportó también la perdida de la dimensión afectiva de la política hoy día, la que se manifiesta por un desinterés generalizado por la política y la incomprensión de lo político en su dimensión ontológica. Así que el arte político en Latinoamérica fue descalificándose y despolitizándose, ya que el mundo estético iba guiado por un lado por el discurso de la Modernidad y por otro por la Vanguardia, las que tienen en común la incomprensión tanto de los vínculos del arte con lo político, como también de la estética como base de lo político. Aún así, no se pueden negar ni el diálogo constante entre el arte y la comunidad ni el "potencial del arte como fuerza movilizadora para crear actos de resistencia". Lo político en el arte ya no resulta del compromiso en organizaciones políticas tradicionales (p.e. partidos políticos) o hacia objetivos políticos precisos (p.e. la Revolución Cubana). Mucho más, lo político en el arte hoy día se expresa por los intentos de participación en y reconfiguración de lo común, como también por la elección de un "común negado". En este caso, es más adecuado hablar de un "activismo artístico", el que se puede definir como "una forma de arte político que utiliza las estrategias tanto del activismo político como del arte". Entendemos el activismo artístico como aquella creación artística que sirve de herramienta política, es decir de medio de autoconciencia, empoderamiento, resistencia y transformación, a nivel tanto individual como colectivo. En este sentido, Violeta Parra fue, más que una artista política, una activista artística (cf. Ibárra Cáceres 2015, Ribeiro Dos Santos 2015).

18. "levántante, Huenchullán”, "levántate Curimón", "levántate Manquilef”, "levántate Callfull”, “ levántate Curimán”, "levántate Quilapán”, "levántate Callupán” (“Arauco tiene una pena” en Engelbert 2017 [1978]: 178-180).

19. "Qué vamos a hacer con tanto/ tratado del alto cielo,/ ayúdame, Valentina,/ ya que tú volaste lejos" (“Ayúdame, Valentina” en Engelbert 2017 [1978]: 182-186).

\section{RESÚMENES}

Durante su vida o después de su muerte, Violeta Parra ha sido doblemente subalternizada: como persona y como artista. El objetivo del presente trabajo es exponer por un lado cuáles fueron estas prácticas de marginalización y cómo ella salió del papel marginal que le otorgaban y se empoderó tanto en su vida privada como en su vida profesional. Por otro lado, se va a demostrar cómo la artista chilena usó la pluma en la mano, llenando el papel (PARRA, 1972) no sólo para dar calma a los tormentos del alma, sino también pa' dar el grito de alarma (ibid.) y luchar contra las opresiones, haciendo de sus versos un potente espacio de enunciación múltiple y empoderamiento del sujeto femenino.

During her lifetime or after her death, Violeta Parra has been rendered the status of the subaltern, both as a person and an artist. This paper aims to show on the one hand what these marginalizing practices were and how Violeta Parra left the marginal position they have been granting her and empowered herself in both her private and professional life. On the other hand, it will be shown how the Chilean artist used la pluma en la mano, llenando el papel not only para dar calma a los tormentos del alma, but also pa' dar el grito de alarma and fight against multiple 
oppressions making out of her verses a powerful space of enunciation and empowerment of the Latin American woman.

\section{ÍNDICE}

Keywords: Violeta Parra, empowerment, subaltern, margins, space of enunciation, subject, Latin American poetry

Palabras claves: Violeta Parra, empoderamiento, subalterno, márgenes, espacio de

\section{AUTOR}

\section{ELENI STAGKOURAKI}

Estudios de cultura latinoamericana

Facultad de Ciencias de Traducción, Lingüistica y Cultura (FTSK)

Universidad Johannes Gutenberg de Maguncia

estagkou(a)uni-mainz.de 